\title{
Relationship between Stage of Kidney Disease and Incident Heart Failure in Older Adults
}

\author{
C. Barrett Bowling ${ }^{a, b} \quad$ Margaret A. Feller ${ }^{b}$ Marjan Mujib ${ }^{b}$ Pushkar P. Pawar ${ }^{b}$ \\ Yan Zhang $^{\text {b }}$ O. James Ekundayo ${ }^{c}$ Inmaculada B. Aban ${ }^{b}$ Thomas E. Love ${ }^{d}$ \\ Paul W. Sanders ${ }^{a, b}$ Stefan D. Anker ${ }^{e, f}$ Gregg C. Fonarow $^{c}$ Ali Ahmed $^{a, b}$

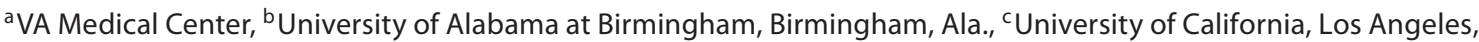 \\ Los Angeles, Calif., and d Case Western Reserve University, Cleveland, Ohio, USA; ${ }^{e}$ Charité Medical School and \\ Campus Virchow-Klinikum, Berlin, Germany; ${ }^{\dagger}$ Centre for Clinical and Basic Research, IRCCS San Raffaele, Rome, Italy
}

\section{Key Words}

Chronic kidney disease $\cdot$ Heart failure

\begin{abstract}
Background: The relationship between stage of chronic kidney disease (CKD) and incident heart failure (HF) remains unclear. Methods: Of the 5,795 community-dwelling adults $\geq 65$ years in the Cardiovascular Health Study, 5,450 were free of prevalent $\mathrm{HF}$ and had baseline estimated glomerular filtration rate (eGFR: $\mathrm{ml} / \mathrm{min} / 1.73 \mathrm{~m}^{2}$ ) data. Of these, 898 (16\%) had CKD 3A (eGFR 45-59 ml/min/1.73 $\mathrm{m}^{2}$ ) and $242(4 \%)$ had CKD stage $\geq 3 B\left(e G F R<45 \mathrm{ml} / \mathrm{min} / 1.73 \mathrm{~m}^{2}\right)$. Data on baseline proteinuria were not available and 4,310 (79\%) individuals with eGFR $\geq 60 \mathrm{ml} / \mathrm{min} / 1.73 \mathrm{~m}^{2}$ were considered to have no CKD. Propensity scores estimated separately for CKD $3 A$ and $\geq 3 B$ were used to assemble two cohorts of 1,714 (857 pairs with CKD $3 A$ and no CKD) and 557 participants (148 CKD $\geq 3 \mathrm{~B}$ and 409 no CKD), respectively, balanced on 50 baseline characteristics. Results: During 13 years of follow-up, centrally-adjudicated incident HF occurred in 19, 24 and $38 \%$ of pre-match participants without CKD (reference), with CKD $3 \mathrm{~A}$ [unadjusted hazard ratio (HR) 1.40; $95 \%$ confidence interval (CI) 1.20-1.63; $p<0.001]$ and with CKD $\geq 3$ B (HR 3.37; 95\%
\end{abstract}

Cl 2.71-4.18; $p<0.001)$, respectively. In contrast, among matched participants, incident HF occurred in 23 and $23 \%$ of those with CKD $3 A$ and no CKD, respectively (HR 1.03; 95\% $\mathrm{Cl} 0.85-1.26 ; p=0.746)$, and 36 and $28 \%$ of those with CKD $\geq 3 \mathrm{~B}$ and no CKD, respectively (HR 1.44; $95 \% \mathrm{Cl} 1.04-2.00$; $p=0.027)$. Conclusions: Among community-dwelling older adults, CKD is a marker of incident HF regardless of stage; however, CKD $\geq 3 \mathrm{~B}$, not CKD 3A, has a modest independent association with incident HF. $\quad$ Copyright $\odot 2011$ S. Karger AG, Basel

Elevated serum creatinine is associated with an increased risk of incident heart failure (HF) $[1,2]$. However, serum creatinine is a poor marker of kidney function, especially among older adults [3]. Although estimated glomerular filtration rate (eGFR) has emerged as a more reliable marker of kidney function, and low eGFR has been shown to be associated with poor outcomes in those with HF [4], little is known about the true association between kidney function, as determined by eGFR and incident HF. The aim of this study was to determine the association between CKD stage and incident HF in propensitymatched cohorts of community-dwelling older adults.

\section{KARGER}

두 2011 S. Karger AG, Basel

Fax +4161306 1234 E-Mail karger@karger.ch www.karger.com www.karger.com/ajn
Ali Ahmed, MD, MPH

1530 3rd Avenue South, CH-19, Suite 219

Birmingham, AL 35294-2041 (USA)

Tel. +1 2059349632

E-Mail aahmed@uab.edu 


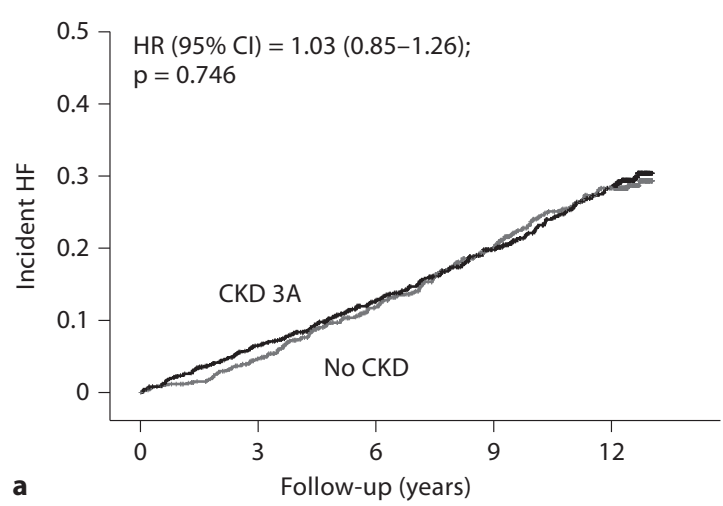

Number of patients at risk

$\begin{array}{lccccc}\begin{array}{l}\text { No CKD } \\ (\text { eGFR } \geq 60)\end{array} & 856 & 782 & 646 & 505 & 356 \\ \text { CKD 3A } & 857 & 751 & 616 & 480 & 350\end{array}$

(eGFR 45-59)

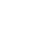

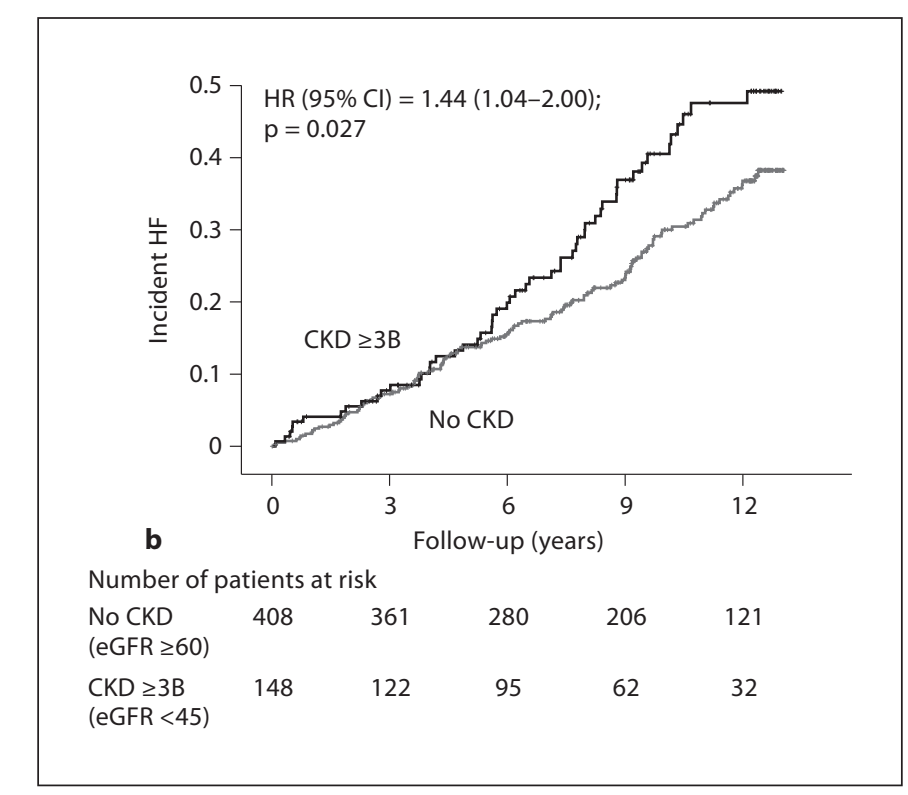

Fig. 1. Kaplan-Meier plots for incident HF by CKD stages: CKD $3 \mathrm{~A}(\mathbf{a})$ and $C K D \geq 3 \mathrm{~B}(\mathbf{b})$.

\section{Methods}

Study Design and Participants

The Cardiovascular Health Study (CHS) is a population-based prospective study of cardiovascular disease in older adults funded by the National Heart, Lung, and Blood Institute (NHLBI). Details of background, design and recruitment process for CHS have been previously reported [1, 2, 5-9]. Briefly, an original cohort of 5,201 community-dwelling older adults (age $\geq 65$ years) was recruited during 1989-1990, and a second cohort of 687 AfricanAmerican participants was recruited during 1992-1993. For this study, we used a de-identified public-use copy of the CHS data, which was obtained from the CHS Coordinating Center through the NHLBI and which is identical to the original CHS data except that 93 participants did not consent to be included in it. Of the 5,795 participants, 78 with missing baseline eGFR data and 267 with baseline HF were excluded, leaving 5,450 participants for the current analysis.

\section{Baseline CKD and Other Measurements}

Of the 5,450 patients, 898 (16\%) had CKD stage $3 \mathrm{~A}$, defined as eGFR $45-59 \mathrm{ml} / \mathrm{min} / 1.73 \mathrm{~m}^{2}$, and estimated using the Chronic Kidney Disease Epidemiology Collaboration (CKD-EPI) equation [10]. Because the deleterious effects of CKD are not often observed until CKD is more advanced $[11,12]$, we also identified 242 (4\%) participants who had stage $\geq 3$ B CKD (eGFR $<45 \mathrm{ml} /$ $\min / 1.73 \mathrm{~m}^{2}$ ). Structural or functional kidney damage for $\geq 3$ months as evidenced by pathological abnormalities in the composition of the blood or urine or in an imaging test is required to define CKD in individuals with eGFR $\geq 60 \mathrm{ml} / \mathrm{min} / 1.73 \mathrm{~m}^{2}$ [13]. However, baseline data on kidney damage were not available from CHS participants. Because the prevalence of albuminuria among those with eGFR $60-89 \mathrm{ml} / \mathrm{min} / 1.73 \mathrm{~m}^{2}$ is low [14], and the vast majority of these individuals likely have no kidney damage, for the purpose of the current analysis, we considered eGFR $\geq 60 \mathrm{ml} /$ $\mathrm{min} / 1.73 \mathrm{~m}^{2}$ as having no CKD.

\section{Assembly of the Balanced Cohorts}

Propensity score matching was used to assemble a cohort of participants with and without CKD who would be balanced in all measured baseline characteristics. Propensity scores for CKD stage $3 \mathrm{~A}$ were estimated for each of the 5,208 participants using a non-parsimonious multivariable logistic regression model $[4,15-$ 20]. In the model, CKD stage $3 \mathrm{~A}$ was used as the dependent variable and the 50 baseline characteristics displayed in figure 1 were entered as covariates. We then used a 1-to-1 matching protocol to assemble a cohort of 857 pairs of participants with CKD stage $3 \mathrm{~A}$ and no CKD who had similar propensity scores.

Propensity score models are sample-specific adjusters and are not intended to be used for out-of-sample prediction or estimation of coefficients. Therefore, absolute standardized differences, rather than measures of fitness and discrimination, are more appropriate for the assessment of the model's effectiveness $[4,5,8$, 15-20]. Absolute standardized differences directly quantify the bias in the means (or proportions) of covariates across the groups, expressed as a percentage of the pooled standard deviations. Therefore, we calculated pre- and post-match absolute standardized differences and presented those findings as Love plots [2126]. An absolute standardized difference of $0 \%$ indicates no residual bias and $<10 \%$ is considered of inconsequential bias.

Then we repeated the above process to assemble a cohort of participants with CKD stage $\geq 3 \mathrm{~B}$ and no CKD (eGFR $\geq 60 \mathrm{ml} /$ $\mathrm{min} / 1.73 \mathrm{~m}^{2}$ ). Because of the small number of participants with CKD stage $\geq 3 B(n=242)$, we used a greedy matching protocol in which 1 participant with CKD stage $\geq 3 \mathrm{~B}$ could be matched with up to 3 participants without CKD. In the end, we were able to 
match 148 participants with CKD stage $\geq 3 \mathrm{~B}$ and 409 participants without CKD, who had similar propensity scores, thus assembling a cohort of 557 participants. Absolute standardized differences for all 50 covariates were estimated and presented as Love plots $[4,15-20,27]$.

\section{Incident HF and Other Outcomes}

The primary outcome for this study was new-onset HF during a median follow-up of over 13 years. Data on incident HF was collected annually and was centrally adjudicated in $\mathrm{CHS}$, the process of which has been well described in the literature [2, 5, 28, 29]. Briefly, a central Events Committee adjudicated the diagnosis of HF based on a constellation of symptoms, physical signs, and other supporting findings suggestive of HF, including the use of medications commonly used for $\mathrm{HF}$, and follow-up surveillances. The CHS criteria for diagnosis of HF has been reported to be more conservative than the criteria used in the Framingham Heart Study, and HF patients diagnosed using either criteria have been reported to have similar all-cause mortality rates [30]. Secondary outcomes include all-cause mortality and other incident cardiovascular events.

\section{Statistical Analysis}

Descriptive analyses included Pearson's $\chi^{2}$ test, Student's t test, the Wilcoxon rank-sum test, and paired sample t test used as appropriate for between-group comparisons. We then used KaplanMeier and Cox proportional hazard analyses to estimate the associations between baseline CKD and outcomes. Proportional hazards assumptions were checked using log-minus-log scale survival plots. We examined the association of baseline CKD stage $3 \mathrm{~A}$ and incident $\mathrm{HF}$ among 5,208 participants and baseline CKD stage $\geq 3 \mathrm{~B}$ and incident $\mathrm{HF}$ among 4,552 participants using unadjusted and multivariable-adjusted models adjusting for all baseline characteristics used in the propensity model. A multivariable adjustment model using the propensity score was also performed. Associations of baseline CKD stage 3A with incident $\mathrm{HF}$ in the propensity-matched cohorts were assessed using Cox regression. A similar analysis was also completed comparing CKD stage $\geq 3 \mathrm{~B}$ to those with no CKD. A formal sensitivity analysis was conducted to quantify the degree of a hidden bias that would need to be present to invalidate our conclusions based on the propensity-matched cohort [31]. All statistical tests were twotailed with $95 \%$ confidence levels and a $p$ value $<0.05$ was considered significant. SPSS for Windows (Release 18, 2009; SPSS Inc., Chicago, Ill., USA) was used for all data analyses.

\section{Results}

\section{Baseline Characteristics}

Before matching, compared to participants without $\mathrm{CKD}$, those with CKD stage $3 \mathrm{~A}$ were more likely to be older and of Caucasian descent. They were also more likely to have coronary artery disease, hypertension, and higher systolic blood pressure (online suppl. table 1, for all online supplementary material see, www. karger.com/doi/10.1159/000328905). These and other baseline characteristics were well balanced after matching (online suppl. fig. 1). Pre-match imbalances and postmatch balances in baseline characteristics between patients with CKD stage $\geq 3 \mathrm{~B}$ and no CKD are displayed in online supplementary table 2 and online supplementary figure 2 .

\section{Association of Baseline CKD with Incident HF}

In the pre-match cohort, incident HF occurred in 24 and $19 \%$ of patients with CKD stage $3 \mathrm{~A}$ and no CKD, respectively [unadjusted hazard ratio (HR) when CKD 3A was compared with no CKD, 95\% confidence intervals (CI) 1.40; 95\% CI 1.20-1.63; p < 0.001] (table 1). Multivariable-adjusted and propensity-adjusted associations of CKD with incident $\mathrm{HF}$ are displayed in table 1. Among the propensity-matched cohort, incident HF occurred in 23 and $23 \%$ of those with CKD stage $3 \mathrm{~A}$ and without CKD (HR 1.03; 95\% CI 0.85-1.26; $\mathrm{p}=0.746$ ) (table 1; fig. 1). No formal sensitivity analysis was conducted due to lack of any significant association between CKD and incident $\mathrm{HF}$.

When we repeated our analysis comparing CKD stage $\geq 3 \mathrm{~B}\left(\mathrm{eGFR}<45 \mathrm{ml} / \mathrm{min} / 1.73 \mathrm{~m}^{2}\right)$ with no CKD, incident HF occurred in $38 \%$ of those with CKD stage $\geq 3 \mathrm{~B}$ and $19 \%$ of those with no CKD (unadjusted HR when $\mathrm{CKD}$ stage $\geq 3 \mathrm{~B}$ is compared with no $\mathrm{CKD}$, 3.37; 95\% CI 2.71-4.18; p < 0.001) (table 1). Multivariable-adjusted and propensity-adjusted associations of CKD with incident $\mathrm{HF}$ are displayed in table 1 . In the propensity-matched cohort, incident HF occurred in $36 \%$ of participants with CKD stage $\geq 3 \mathrm{~B}$ and $28 \%$ of those with no CKD (HR 1.44; 95\% CI 1.04-2.00; $\mathrm{p}=0.027$ ) (table 1). Findings from the Kaplan-Meier survival analysis suggest that the increased incidence of HF among those with CKD stage $\geq 3 \mathrm{~B}$ compared to the no CKD group did not occur until after 5 years of follow-up (fig. 1). In the absence of a hidden bias, a sign-score test for matched data with censoring provides evidence $(\mathrm{p}=$ 0.117 ) that the incidence of HF did not significantly vary between older adults with CKD stage $\geq 3 \mathrm{~B}$ and those with no CKD.

\section{Association of Baseline CKD with Other Outcomes}

Compared to the no CKD group, both CKD stage 3A and stage $\geq 3 \mathrm{~B}$ were associated with an increased risk of all-cause mortality, both before and after matching (table 2). Associations of baseline CKD stages $3 \mathrm{~A}$ and $\geq 3 \mathrm{~B}$ with other outcomes are displayed in table 2 . 
Table 1. Association of CKD stage with incident HF

\begin{tabular}{|c|c|c|c|c|c|}
\hline & \multicolumn{2}{|c|}{ Events, n (\%) } & \multirow{2}{*}{$\begin{array}{l}\text { Absolute risk } \\
\text { difference }^{1}, \%\end{array}$} & \multirow{2}{*}{$\begin{array}{l}\text { Hazard ratio } \\
(95 \% \mathrm{CI})\end{array}$} & \multirow[t]{2}{*}{$\mathrm{p}$ value } \\
\hline & no CKD & CKD 3A & & & \\
\hline Before matching $(\mathrm{n}=5,208)$ & 4,310 & 898 & & & \\
\hline Unadjusted & $824(19)$ & $213(24)$ & +5 & $1.40(1.20-1.63)$ & $<0.001$ \\
\hline Multivariable-adjusted & & & & $1.00(0.85-1.18)$ & 0.967 \\
\hline Propensity-adjusted & & & & $1.01(0.86-1.19)$ & 0.870 \\
\hline After matching $(\mathrm{n}=1,714)$ & 857 & 857 & & & \\
\hline \multirow[t]{2}{*}{ Propensity-matched } & $200(23)$ & $200(23)$ & 0 & $1.03(0.85-1.26)$ & 0.746 \\
\hline & no CKD & $\mathrm{CKD} \geq 3 \mathrm{~B}$ & & & \\
\hline Before matching $(\mathrm{n}=4,552)$ & 4,310 & 242 & & & \\
\hline Unadjusted & $824(19)$ & $92(38)$ & +8 & $3.37(2.71-4.18)$ & $<0.001$ \\
\hline Multivariable-adjusted & & & & $1.59(1.24-2.05)$ & $<0.001$ \\
\hline Propensity-adjusted & & & & $1.48(1.10-2.00)$ & 0.009 \\
\hline After matching $(\mathrm{n}=557)$ & 409 & 148 & & & \\
\hline Propensity-matched & $115(28)$ & $53(36)$ & +8 & $1.44(1.04-2.00)$ & 0.027 \\
\hline
\end{tabular}

${ }^{1}$ Absolute risk differences were calculated by subtracting the percentage of events in the no CKD group from those in the CKD $3 \mathrm{~A}$ and $\mathrm{CKD} \geq 3 \mathrm{~B}$ groups before rounding, respectively.

Table 2. Hazard ratios (95\% CI) for other outcomes by CKD

\begin{tabular}{|c|c|c|c|c|}
\hline & \multicolumn{2}{|l|}{ Before matching } & \multicolumn{2}{|l|}{ After matching } \\
\hline & hazard ratio $(95 \% \mathrm{CI})$ & $\mathrm{p}$ value & hazard ratio $(95 \% \mathrm{CI})$ & $\mathrm{p}$ value \\
\hline \multicolumn{5}{|l|}{ CKD $3 \mathrm{~A}$} \\
\hline All-cause mortality & $1.61(1.46-1.78)$ & $<0.001$ & $1.20(1.05-1.36)$ & 0.008 \\
\hline Acute myocardial infarction & $1.26(1.02-1.56)$ & 0.032 & $1.10(0.83-1.46)$ & 0.505 \\
\hline Stroke & $1.37(1.13-1.66)$ & 0.002 & $1.27(0.98-1.65)$ & 0.066 \\
\hline Transient ischemic attack & $1.27(0.86-1.87)$ & 0.227 & $0.98(0.60-1.62)$ & 0.946 \\
\hline Peripheral artery disease & $1.97(1.42-2.72)$ & $<0.001$ & $1.43(0.93-2.21)$ & 0.100 \\
\hline \multicolumn{5}{|l|}{$\mathrm{CKD} \geq 3 \mathrm{~B}$} \\
\hline All-cause mortality & $3.30(2.84-3.84)$ & $<0.001$ & $1.33(1.05-1.67)$ & 0.018 \\
\hline Acute myocardial infarction & $1.74(1.18-2.57)$ & 0.005 & $0.84(0.46-1.52)$ & 0.569 \\
\hline Stroke & $2.26(1.63-3.13)$ & $<0.001$ & $1.36(0.87-2.11)$ & 0.177 \\
\hline Transient ischemic attack & $2.79(1.61-4.85)$ & $<0.001$ & $1.47(0.63-3.43)$ & 0.375 \\
\hline Peripheral artery disease & $3.66(2.26-5.93)$ & $<0.001$ & $1.55(0.75-3.19)$ & 0.237 \\
\hline
\end{tabular}

\section{Discussion}

The findings of the current study suggest that although CKD stage $3 \mathrm{~A}$ (eGFR $45-59 \mathrm{ml} / \mathrm{min} / 1.73 \mathrm{~m}^{2}$ ) was a predictor of incident HF among community-dwelling older adults, this association lacked independence. In contrast, a more advanced CKD stage $\geq 3 \mathrm{~B}$ was a stronger predictor of incident HF, which also had a modest inde- pendent association. We also observed that both CKD stages were associated with increased mortality. To the best of our knowledge, this is the first report of the relationship between various baseline CKD stages and incident HF from a prospective cohort study of communitydwelling older adults. These findings are important as they suggest that although CKD is an important predictor of incident HF, it may not be a risk factor for incident 
HF until it reaches an advanced stage, and even when CKD is more advanced, it may be only a modest risk factor with a late effect.

The disappearance of the significant unadjusted association between CKD stage $3 \mathrm{~A}$ and incident $\mathrm{HF}$ after risk adjustments using various methods including propensity score matching suggest that the association was likely not intrinsic in nature and was the result of confounding by imbalances in baseline risk factors. Although the baseline prevalence of hypertension was similar between those with CKD stage $\geq 3 \mathrm{~B}$ (vs. those with no CKD), those with CKD stage $\geq 3 \mathrm{~B}$ may have developed hypertension at a higher rate and hypertension in those individuals may have been more difficult to control, thus explaining the independent increased risk of HF. It is also possible that a more severe impairment of sodium and fluid balance in CKD stage $\geq 3 \mathrm{~B}$ may have expedited the development of clinical HF in those patients. An activated renin-angiogensin-aldosterone system and sympathetic nervous system in advanced CKD may also have increased their risk for new-onset HF $[32,33]$. Finally, oxidative stress, inflammation, hypercoagulablity, and endothelial dysfunction associated with advanced CKD may have played a role in increasing the risk of incident HF [34-37].

Although findings from our sensitivity analysis suggest that the association of CKD stage $\geq 3 \mathrm{~B}$ with incident HF may be sensitive to an unmeasured confounder, sensitivity analysis cannot determine whether such an unmeasured confounder actually exists or not. To be a confounder, an unmeasured covariate, in addition to being associated with CKD, would also need to have a nearperfect association with incident $\mathrm{HF}$ and not have a strong association with any of the 50 measured baseline covariates used in our study, a possibility which seems highly unlikely. Further, because the sign-score test used in the sensitivity analysis is based on ranks of the data rather than their actual values, it is considerably less powerful than the matched Cox survival analysis, which may also in part explain the non-significant sensitivity analysis. Therefore, while the association between CKD stage $\geq 3 \mathrm{~B}$ and incident HF based on our matched Cox survival analysis results are statistically significant, the conclusions may not be robust, and need to be viewed as preliminary and replicated in future studies.

The association between serum creatinine and incident HF is well recognized $[1,2]$. However, serum creatinine concentration is affected by factors other than GFR [11]. Several other studies have also examined the association between CKD and incident HF [38, 39]. However, our study is distinguished by the use of CKD-EPI for- mula to estimate GFR, use of various CKD stages, central adjudication of HF, longer follow-up, and a host of other outcomes. Major HF guidelines either do not mention $\mathrm{CKD}$ as an etiologic risk factor or mention 'end-stage renal failure' as a risk factor for HF [40, 41]. Findings from our study confirm that CKD stage $3 \mathrm{~A}$ is not an independent risk factor, stage $\geq 3 \mathrm{~B}$ may be, and the risk of $\mathrm{HF}$ among those with CKD stage $\geq 3 \mathrm{~B}$ was not immediate. These observations would suggest that there might be a window of opportunity to prevent HF in those with CKD. However, whether more aggressive management of risk factors would be more effective in reducing the risk of incident HF is currently unknown and will need to be determined in future prospective studies.

There were several limitations to our study. Because CHS participants are community-dwelling older adults and many had no CKD, we used CKD-EPI to estimate eGFR and define CKD. Unlike the commonly used Modification of Diet in Renal Disease formula to estimate GFR [11], the CKD-EPI is more reliable in those with eGFR $>60 \mathrm{ml} / \mathrm{min} / 1.73 \mathrm{~m}^{2}$. However, the CKD-EPI has not been validated in older adults and misclassification is possible. It is also possible that participants without CKD developed CKD during follow-up, and it is possible that the resultant regression dilution may in part explain the non-significant findings of our study.

In conclusion, among community-dwelling older adults, CKD is a predictor of incident HF regardless of stage and $\mathrm{CKD}$ stage $\geq 3 \mathrm{~B}$ may have an independent modest association with incident HF.

\section{Acknowledgements}

Dr. Ahmed is supported by the National Institutes of Health (grants R01-HL085561 and R01-HL097047) from the National Heart, Lung, and Blood Institute and a generous gift from Ms. Jean B. Morris of Birmingham, Alabama. Dr. Sanders is supported by the National Institutes of Health (grants R01-DK046199 and P30-DK079337) and a Merit Award from the Department of Veterans Affairs. Dr. Bowling is supported by the Birmingham/Atlanta GRECC Special Fellowship in Advanced Geriatrics, the John A. Hartford Foundation and the Southeast Center of Excellence in Geriatric Medicine.

\section{Disclosure Statement}

This article was prepared using a limited access dataset obtained by the NHLBI and does not necessarily reflect the opinions or views of the CHS or the NHLBI. 


\section{References}

${ }_{1}$ Fried LF, Shlipak MG, Crump C, Bleyer AJ, Gottdiener JS, Kronmal RA, Kuller LH, Newman AB: Renal insufficiency as a predictor of cardiovascular outcomes and mortality in elderly individuals. J Am Coll Cardiol 2003;41:1364-1372.

\2 Gottdiener JS, Arnold AM, Aurigemma GP, Polak JF, Tracy RP, Kitzman DW, Gardin JM, Rutledge JE, Boineau RC: Predictors of congestive heart failure in the elderly: the Cardiovascular Health Study. J Am Coll Cardiol 2000;35:1628-1637.

- 3 Swedko PJ, Clark HD, Paramsothy K, Akbari A: Serum creatinine is an inadequate screening test for renal failure in elderly patients. Arch Intern Med 2003;163:356-360.

- 4 Ahmed A, Rich MW, Sanders PW, Perry GJ, Bakris GL, Zile MR, Love TE, Aban IB, Shlipak MG: Chronic kidney disease associated mortality in diastolic versus systolic heart failure: a propensity-matched study. Am J Cardiol 2007;99:393-398.

$\checkmark 5$ Ekundayo OJ, Allman RM, Sanders PW, Aban I, Love TE, Arnett D, Ahmed A: Isolated systolic hypertension and incident heart failure in older adults: a propensitymatched study. Hypertension 2009;53:458465.

-6 Iyer AS, Ahmed MI, Filippatos GS, Ekundayo OJ, Aban IB, Love TE, Nanda NC, Bakris GL, Fonarow GC, Aronow WS, Ahmed A: Uncontrolled hypertension and increased risk for incident heart failure in older adults with hypertension: findings from a propensity-matched prospective population study. J Am Soc Hypertens 2010;4: 22-31.

7 Ekundayo OJ, Howard VJ, Safford MM, McClure LA, Arnett D, Allman RM, Howard G, Ahmed A: Value of orthopnea, paroxysmal nocturnal dyspnea, and medications in prospective population studies of incident heart failure. Am J Cardiol 2009;104:259-264.

$\checkmark 8$ Ekundayo OJ, Dell'Italia LJ, Sanders PW, Arnett D, Aban I, Love TE, Filippatos G, Anker SD, Lloyd-Jones DM, Bakris G, Mujib M, Ahmed A: Association between hyperuricemia and incident heart failure among older adults: a propensity-matched study. Int J Cardiol 2010;142:279-287.

$\checkmark 9$ Fried LP, Borhani NO, Enright P, Furberg CD, Gardin JM, Kronmal RA, Kuller LH, Manolio TA, Mittelmark MB, Newman A, et al: The Cardiovascular Health Study: design and rationale. Ann Epidemiol 1991;1:263276.

10 Levey AS, Stevens LA, Schmid CH, Zhang YL, Castro AF 3rd, Feldman HI, Kusek JW, Eggers P, Van Lente F, Greene T, Coresh J: A new equation to estimate glomerular filtration rate. Ann Intern Med 2009;150:604612 .
1 Levey AS, Bosch JP, Lewis JB, Greene T, Rogers N, Roth D: A more accurate method to estimate glomerular filtration rate from serum creatinine: a new prediction equation. Modification of Diet in Renal Disease Study Group. Ann Intern Med 1999;130:461-470.

12 Kirsztajn GM, Suassuna JH, Bastos MG: Dividing stage 3 of chronic kidney disease (CKD): 3a and 3b. Kidney Int 2009;76:462464.

13 National Kidney F: K/DOQI clinical practice guidelines for chronic kidney disease: evaluation, classification, and stratification. Am J Kidney Dis 2002;39:S1-S266.

-14 Coresh J, Selvin E, Stevens LA, Manzi J, Kusek JW, Eggers P, Van Lente F, Levey AS: Prevalence of chronic kidney disease in the United States. JAMA 2007;298:2038-2047.

15 Rosenbaum PR, Rubin DB: The central role of propensity score in observational studies for causal effects. Biometrika 1983;70:41-55.

16 Rubin DB: Using propensity score to help design observational studies: application to the tobacco litigation. Health Serv Outcomes Res Methodol 2001;2:169-188.

17 Ahmed A, Husain A, Love TE, Gambassi G, Dell'Italia LJ, Francis GS, Gheorghiade M, Allman RM, Meleth S, Bourge RC: Heart failure, chronic diuretic use, and increase in mortality and hospitalization: an observational study using propensity score methods. Eur Heart J 2006;27:1431-1439.

18 Ahmed A, Perry GJ, Fleg JL, Love TE, Goff DC Jr, Kitzman DW: Outcomes in ambulatory chronic systolic and diastolic heart failure: a propensity score analysis. Am Heart J 2006;152:956-966.

19 Ritchie C, Ekundayo OJ, Muchimba M, Campbell RC, Frank SJ, Liu B, Aban IB, Ahmed A: Effects of diabetes mellitus in patients with heart failure and chronic kidney disease: a propensity-matched study of multimorbidity in chronic heart failure. Int J Cardiol 2009;134:330-335.

20 Bowling CB, Pitt B, Ahmed MI, Aban IB, Sanders PW, Mujib M, Campbell RC, Love TE, Aronow WS, Allman RM, Bakris GL, Ahmed A: Hypokalemia and outcomes in patients with chronic heart failure and chronic kidney disease: findings from propensity-matched studies. Circ Heart Fail 2010;3:253-260.

21 Banach M, Bhatia V, Feller MA, Mujib M, Desai RV, Ahmed MI, Guichard JL, Aban I, Love TE, Aronow WS, White M, Deedwania P, Fonarow G, Ahmed A: Relation of baseline systolic blood pressure and long-term outcomes in ambulatory patients with chronic mild to moderate heart failure. Am J Cardiol 2011;107:1208-1214.
22 Mujib M, Desai RV, Ahmed MI, Guichard JL, Feller MA, Ekundayo OJ, Deedwania P, Ali M, Aban IB, Love TE, White M, Aronow WS, Rahimtoola SH, Bonow RO, Ahmed A: Rheumatic heart disease and risk of incident heart failure among community-dwelling older adults: a prospective cohort study. Ann Med 2011 DOI: 10.3109/07853890. 2010.530685

-23 Filippatos GS, Ahmed MI, Gladden JD, Mujib M, Aban IB, Love TE, Sanders PW, Pitt B, Anker SD, Ahmed A: Hyperuricaemia, chronic kidney disease, and outcomes in heart failure: potential mechanistic insights from epidemiological data. Eur Heart J 2011; 32:712-720.

24 Mujib M, Rahman AA, Desai RV, Ahmed MI, Feller MA, Aban I, Love TE, White M, Deedwania P, Aronow WS, Fonarow G, Ahmed A: Warfarin use and outcomes in patients with advanced chronic systolic heart failure without atrial fibrillation, prior thromboembolic events, or prosthetic valves. Am J Cardiol 2011;107:552-557.

25 Adamopoulos C, Meyer P, Desai RV, Karatzidou K, Ovalle F, White M, Aban I, Love TE, Deedwania P, Anker SD, Ahmed A: Absence of obesity paradox in patients with chronic heart failure and diabetes mellitus: a propensity-matched study. Eur J Heart Fail 2011;13: 200-206.

-26 Kvale E, Ekundayo OJ, Zhang Y, Akhter S, Aban I, Love TE, Ritchie C, Ahmed A: History of cancer and mortality in communitydwelling older adults. Cancer Epidemiol 2011;35:30-36.

27 Normand ST, Landrum MB, Guadagnoli E, Ayanian JZ, Ryan TJ, Cleary PD, McNeil BJ: Validating recommendations for coronary angiography following acute myocardial infarction in the elderly: a matched analysis using propensity scores. J Clin Epidemiol 2001; 54:387-398

28 Psaty BM, Kuller LH, Bild D, Burke GL, Kittner SJ, Mittelmark M, Price TR, Rautaharju PM, Robbins J: Methods of assessing prevalent cardiovascular disease in the Cardiovascular Health Study. Ann Epidemiol 1995;5:270-277.

29 Ives DG, Fitzpatrick AL, Bild DE, Psaty BM, Kuller LH, Crowley PM, Cruise RG, Theroux S: Surveillance and ascertainment of cardiovascular events. The Cardiovascular Health Study. Ann Epidemiol 1995;5:278-285.

30 Schellenbaum GD, Rea TD, Heckbert SR, Smith NL, Lumley T, Roger VL, Kitzman DW, Taylor HA, Levy D, Psaty BM: Survival associated with two sets of diagnostic criteria for congestive heart failure. Am J Epidemiol 2004;160:628-635.

31 Rosenbaum PR: Sensitivity to hidden bias; in Rosenbaum PR (ed): Observational Studies. New York, Springer, 2002, vol 1, pp 105-170. 
-32 Siragy HM, Carey RM: Role of the intrarenal renin-angiotensin-aldosterone system in chronic kidney disease. Am J Nephrol 2010; 31:541-550.

33 Chen Y, Lipkowitz MS, Salem RM, Fung MM, Bhatnagar V, Mahata M, Nievergelt CM, Rao F, Mahata SK, Schork NJ, Hicks PJ, Bowden DW, Freedman BI, Brophy VH, O'Connor DT, Aask: Progression of chronic kidney disease: adrenergic genetic influence on glomerular filtration rate decline in hypertensive nephrosclerosis. Am J Nephrol 2010;32:23-30.

-34 Shlipak MG, Fried LF, Crump C, Bleyer AJ, Manolio TA, Tracy RP, Furberg CD, Psaty BM: Elevations of inflammatory and procoagulant biomarkers in elderly persons with renal insufficiency. Circulation 2003;107: 87-92.

-35 Annuk M, Zilmer M, Lind L, Linde T, Fellstrom B: Oxidative stress and endothelial function in chronic renal failure. J Am Soc Nephrol 2001;12:2747-2752.

-36 Schiffrin EL, Lipman ML, Mann JF: Chronic kidney disease: effects on the cardiovascular system. Circulation 2007;116:85-97.
-37 Tetzner F, Scholze A, Wittstock A, Zidek W, Tepel M: Impaired vascular reactivity in patients with chronic kidney disease. Am J Nephrol 2008;28:218-223.

38 Bibbins-Domingo K, Lin F, Vittinghoff E, Barrett-Connor E, Hulley SB, Grady D, Shlipak MG: Predictors of heart failure among women with coronary disease. Circulation 2004;110:1424-1430.

39 Chae CU, Albert CM, Glynn RJ, Guralnik JM, Curhan GC: Mild renal insufficiency and risk of congestive heart failure in men and women $\geq 70$ years of age. Am J Cardiol 2003;92:682-686

40 Task Force for Diagnosis and Treatment of Acute and Chronic Heart Failure 2008 of European Society of Cardiology, Dickstein K, Cohen-Solal A, Filippatos G, McMurray JJ, Ponikowski P, Poole-Wilson PA, Strömberg A, van Veldhuisen DJ, Atar D, Hoes AW, Keren A, Mebazaa A, Nieminen M, Priori SG, Swedberg K; ESC Committee for Practice Guidelines, Vahanian A, Camm J, De Caterina R, Dean V, Dickstein K, Filippatos G, Funck-Brentano C, Hellemans I, Kristensen
SD, McGregor K, Sechtem U, Silber S, Tendera M, Widimsky P, Zamorano JL: ESC Guidelines for the diagnosis and treatment of acute and chronic heart failure 2008: the Task Force for the Diagnosis and Treatment of Acute and Chronic Heart Failure 2008 of the European Society of Cardiology. Developed in collaboration with the Heart Failure Association of the ESC (HFA) and endorsed by the European Society of Intensive Care Medicine (ESICM). Eur Heart J 2008;29:2388-2442.

41 Hunt SA, Abraham WT, Chin MH, Feldman AM, Francis GS, Ganiats TG, Jessup M, Konstam MA, Mancini DM, Michl K, Oates JA, Rahko PS, Silver MA, Stevenson LW, Yancy CW: 2009 focused update incorporated into the ACC/AHA 2005 Guidelines for the Diagnosis and Management of Heart Failure in Adults: a report of the American College of Cardiology Foundation/American Heart Association Task Force on Practice Guidelines: developed in collaboration with the International Society for Heart and Lung Transplantation. Circulation 2009;119:e391e479. 